\title{
Fluoroscopic Cranial Radiation Exposure in Spine Surgery: A Prospective Single-Center Evaluation in Operating Room Personnel
}

\author{
LAILA MALANI MOHAMMAD, MD, JAMES MESSEGEE, MD, M. OMAR CHOHAN, MD, CHRISTOPHER \\ L. TAYLOR, MD, MBA \\ Department of Neurosurgery, University of New Mexico School of Medicine, Albuquerque, New Mexico
}

\begin{abstract}
Background: Cranial radiation exposure during instrumented spine surgery is not well documented. We set out to measure this risk to the patient, surgeon, surgical resident, and scrub technician during these procedures.

Methods: Forty-seven individuals were enrolled during a 1.5-year period between October 2014 and March 2016 at the University of New Mexico Department of Neurosurgery. Radiation doses were obtained through electronic dosimeters placed on the surgical cap over the temporal scalp (bilaterally on surgeon and resident assist, unilaterally on surgical scrub on the side facing radiation source) and on the midline of the patient's exposed cranium.

Results: Of the 47 procedures, $39(83 \%)$ were open and $8(17 \%)$ were minimally invasive or percutaneous instrumented procedures. A total of 91 motion segments were treated, with a mean of 1.9 levels per case $(57 \%$ lumbosacral, $34 \%$ cervical, and $2.1 \%$ thoracic). Total fluoroscopic time was 12.9 minutes. Mean dose per case (mrem/ case) was calculated for the spine surgeon (1.4), resident assist (1.4), surgical scrub (1.2), and the patient (3.6). All doses were within federal safety guidelines. A spine surgeon would need to perform more than 1400 cases per year to reach the current federal maximum permissible dose for head exposure.

Conclusions: There was no difference in cranial radiation exposure between operating room staff during spine surgeries. Moreover, the doses measured at the cranium were within national safety limits. Current protective technologies have significantly reduced the amount of ionizing radiation exposure during routine spine procedures; however, changes in behavior or equipment may further reduce radiation exposure to health care workers.

Clinical Relevance: Radiation exposure to patients and hospital staff remains a major concern in the practice of modern spine surgery. Cranial exposure remains the only established environmental risk factor for brain tumors, such as gliomas and meningiomas. Our study shows that all those exposed to radiation during spine surgery had cranial doses well within the national safety limits.
\end{abstract}

Other \& Special Categories

Keywords: cranial radiation, exposure, radiation, spinal surgery

With the universal use of fluoroscopic guidance during spine procedures, concern for radiation exposure to patients and hospital personnel remains a major worry. ${ }^{1,2}$ Within the general context of radiation exposure, most workers exposed to manmade radiation are now medical personnel. ${ }^{3}$ Although scatter radiation exposure to the lens of the eye and regions below the neck have been quantified and minimized using a variety of personal protective equipment, ${ }^{4-10}$ not much literature is available on exposure to the forehead and skull. ${ }^{11-13}$

Cranial radiation exposure remains a major risk factor for the development of cataracts and brain tumors, including gliomas and meningiomas. ${ }^{11,14-22}$ According to federal safety guidelines from the
Interventional Commission on Radiological Protection (ICRP), exposure to the lens of the eye (and extrapolated to head exposure) should be limited to $20 \mathrm{mSV}$ (2000 mrem) per year. ${ }^{23}$ Our own data from the cranial angiography suite suggest considerable cranial radiation exposure to the operating interventionalist and circulating nurse. ${ }^{24}$

Currently, the literature on cranial radiation exposure in fluoroscopy-guided spine surgery has focused on exposure to the surgeon's torso, ${ }^{25-27}$ neck, or hand. ${ }^{26,28}$ However, there is little literature on cranial exposure to either the patient or operating room staff. Based on our previous observations during cranial angiography, ${ }^{24}$ we performed a prospective study evaluating radiation 


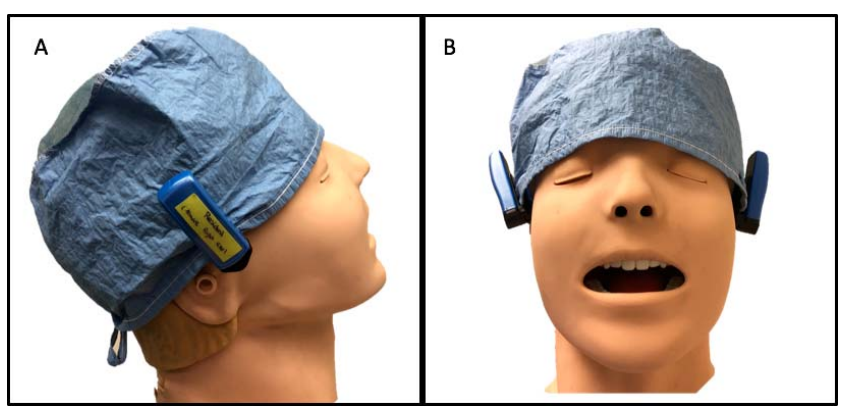

Figure 1. Placement of dosimeter badges on the outside of the scrub cap for both primary surgeon and resident assistant on each temporal scalp area. (A) Lateral view. (B) Profile view.

exposure to the cranium during spine procedures, where the use of fluoroscopy is universal.

\section{METHODS}

All patients older than 18 years, who underwent instrumented or noninstrumented spine procedures that required the use of intraoperative fluoroscopy at the Department of Neurosurgery, University of New Mexico Hospital, between February 2014 and June 2016, were prospectively enrolled in the study. Vulnerable populations, including minors, pregnant women, and incarcerated individuals, were excluded from the study. Patients were enrolled prospectively. Instadose, electronic direct ion storage dosimeter badges (Mirion Technologies, Irvine, California), certified by the National Voluntary Laboratory Accreditation Program, were worn by the primary operating surgeon, surgical resident, operating scrub technician, and the patient undergoing the surgical procedure. Institutional Review Board approval was completed through the University of New Mexico Institutional Review Board.

The primary surgeon and assistant wore two badges, one on each side over the temporal scalp, affixed to the surgical cap (Figure 1). The scrub technician wore one badge over the temporal scalp facing toward the source of ionizing radiation. The patient's badge was placed in the center of the forehead or occiput, facing upward for the entirety of the procedure (Figure 2). Because of low radiation doses overall, which were below the dosimeter detectable limit, 10 cases of cumulative radiation doses at a time were read from the dosimeters and subsequently averaged. Data were compiled and analyzed retrospectively using Microsoft Excel, 2016 (Microsoft Corp, Redmond, Washington).

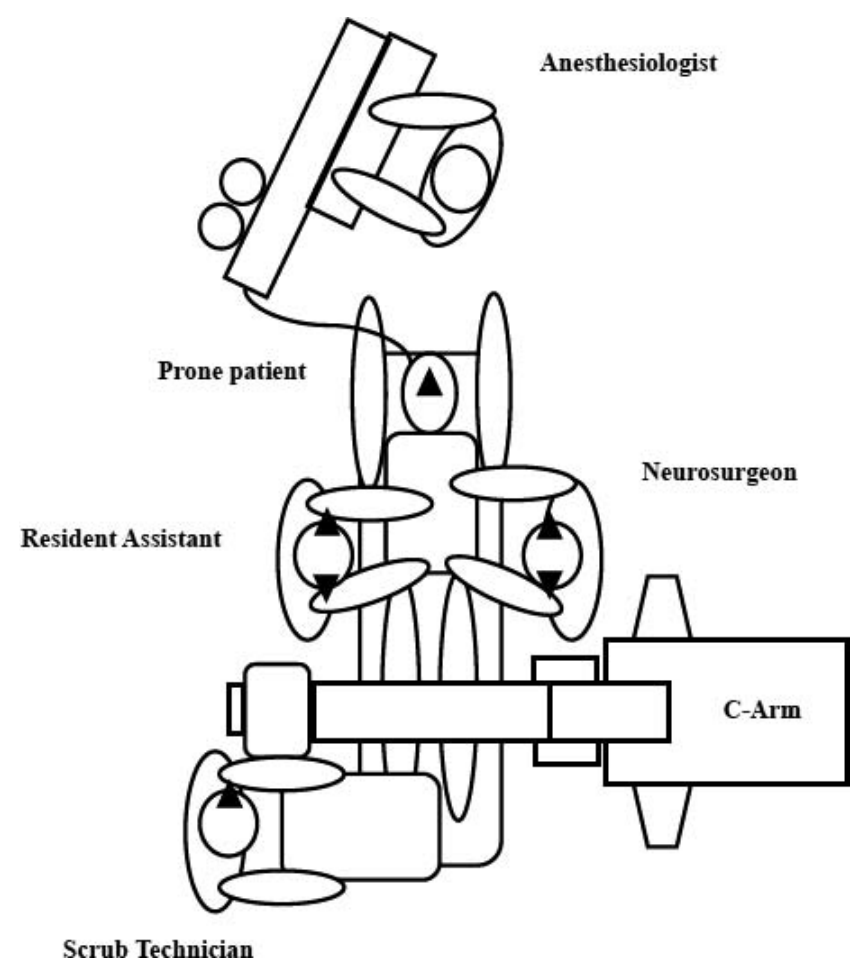

Figure 2. Operating room setup. Black upward arrow represents the dosimeter badge.

\section{RESULTS}

A total of 47 patients were prospectively enrolled in the study. Of these, $39(83 \%)$ were treated with an open approach, and $8(17 \%)$ were minimally invasive (MIS) or percutaneous procedures. No significant difference in radiation delivered via fluoroscopy machine (C-arm) was noted for MIS versus open approaches $(P=.79$ using Student 2tailed $t$-test). A total of 91 motion segments were treated, with a mean of 1.9 levels per case $(57 \%$ lumbosacral, $34 \%$ cervical, and $2.1 \%$ thoracic). Radiation dose received at the dosimeters per case was averaged for the spine surgeon (1.4 mrem), resident assistant (1.4 mrem), surgical scrub technician (1.2 mrem), and the patient (3.6 mrem; Table). A spine surgeon would need to perform more than 1400 cases per year to reach the current federal maximum permissible head exposure dose and more

Table. Dosimetry measurements in vivo and extrapolated annual exposure.

\begin{tabular}{lcccc}
\hline & $\begin{array}{c}\text { Total Fluoroscopic } \\
\text { Radiation } \\
\text { Exposure, mrem }\end{array}$ & $\begin{array}{c}\text { Mean } \\
\text { Dose/Case, } \\
\text { mrem }\end{array}$ & $\begin{array}{c}\text { Mean } \\
\text { Dose/Level, } \\
\text { mrem }\end{array}$ & $\begin{array}{c}\text { Mean Dose/y } \\
\text { per 250 } \\
\text { Cases, mrem }\end{array}$ \\
\hline Attending & 66 & 1.4 & 0.7 & 251.1 \\
Resident & 68 & 1.4 & 0.7 & 361.7 \\
Scrub & 57 & 1.2 & 0.6 & 303.2 \\
Patient & 167 & 3.6 & 1.8 & - \\
\hline
\end{tabular}


than 3500 cases per year to reach the whole-body deep permissible dose.

\section{DISCUSSION}

Radiation exposure to patients and hospital staff remains a major concern in the practice of modern spine surgery. ${ }^{1,2}$ The majority of man-made sources of radiation exposure is to medical personnel. ${ }^{3}$ Moreover, cranial exposure remains the only established environmental risk factor for brain tumors, such as gliomas and meningiomas. ${ }^{11,14-22}$

In 1929, what is now the National Committee on Radiation Protection and Measurements was established to provide the public with recommendations on radiation safety. ${ }^{29}$ This need arose from the developments of atomic and nuclear weapons during World War II. Although no dose is considered without risk, the ICRP has established $20 \mathrm{mSV}$ (2000 mrem) per year as the head exposure limit. $^{23}$

A study by Mariscalco et $\mathrm{al}^{30}$ compared radiation exposure to a surgeon's thyroid/eye, chest, and hand in open discectomy cases versus minimally invasive lumbar microdiscectomy cases. They demonstrated that a surgeon would have to perform only 1623 minimally invasive microdiscectomies in their lifetime to surpass the amount of whole-body radiation of 5000 mrem deemed safe for occupational exposure. $^{30}$ Another study by Amoretti et $\mathrm{al}^{13}$ measured the amount of radiation exposed to the left orbit of the operating surgeon during computed tomography (CT)-guided and fluoroscopy-guided percutaneous vertebroplasty to be a cumulative irradiation dose of $0.14 \mathrm{mSV}$. An in vivo study by Mulconrey $^{25}$ placed unprotected dosimeters on the surgeon's and first assistant's chests, and they estimated that they could be exposed to a maximum of 453 minutes of radiation to remain below the yearly permissible dose.

Available literature on radiation exposure in fluoroscopy-guided spine surgery is focused on exposure to the surgeon's torso, neck, or hand, whereas studies on cranial exposure remain scarce. ${ }^{4-6,8,12,13,17,28,30,31}$ We therefore sought to determine cranial radiation exposure to the patient, surgeon, and operating room personnel during spine surgeries requiring fluoroscopic guidance.

The ICRP guidelines limit exposure to the lens of the eye, and therefore the head, to $20 \mathrm{mSV}$ (20 000 mrem) during a 5-year period. ${ }^{23} \mathrm{~A}$ head CT scan is $2.0 \mathrm{mSV}$ (2000 mrem), whereas the average radia- tion dose received by the spine surgeon, resident assistant, surgical scrub technician, and patient is a fraction of that amount. ${ }^{32}$

In addition, our results demonstrated that there was no statistical difference in cranial radiation among operating room staff during fluoroscopic spinal surgeries. The patient's dosage, however, was 3 times that of the staff. Even with these differences, all those exposed to the radiation were well within the national safety limits, according to the ICRP. ${ }^{23}$ Therefore, a spine surgeon would need to perform more than 1400 cases per year to reach the current federal maximum permissible head exposure dose.

The strength of the study is that the dosimeters are placed directly over the skull caps of the operating room personnel and on both sides of the scalp of the operating surgeon and resident. Previous studies have placed dosimeter badges on the chest and extrapolated radiation doses to the cranium. ${ }^{25}$ Limitations of our study included the quality of the dosimeters themselves. The accuracy of the dosimeters is found to have a $25 \%$ to $35 \%$ error rate. Even with that margin of error, the detectable dose is so low that the current radiation exposure is still found to be minimal. Our study suggests that the current fluoroscopic radiation exposure is well below the federal maximum permissible dose for operating surgeons, residents, scrub technicians, and the patient.

\section{CONCLUSIONS}

In summary, the current study is the first of its kind to directly study cranial radiation exposure during spine surgeries. We found no difference in cranial radiation exposure between operating room staff during spine surgeries. Moreover, the doses measured at the cranium were within national safety limits. Current protective technologies have significantly reduced the amount of ionizing radiation exposure during routine spine procedures; however, changes in behavior or equipment may further reduce radiation exposure to health care workers.

\section{ACKNOWLEDGMENTS}

The authors wish to acknowledge the efforts of Dr Howard Yonas, chair of the Department of Neurosurgery at the University of New Mexico, in support of this research. 


\section{REFERENCES}

1. Singer G. Occupational radiation exposure to the surgeon. J Am Acad Orthop Surg. 2005;13(1):69-76.

2. Theocharopoulos N, Perisinakis K, Damilakis J, Papadokostakis G, Hadjipavlou A, Gourtsoyiannis N. Occupational exposure from common fluoroscopic projections used in orthopaedic surgery. J Bone Joint Surg Am. 2003;85A(9):1698-1703.

3. Charles M. UNSCEAR report 2000: sources and effects of ionizing radiation. United Nations Scientific Comittee on the Effects of Atomic Radiation. J Radiol Prot Off $J$ Soc Radiol Prot. 2001;21(1):83-86.

4. d'Othée BJ, d'Othée BJ, Lin PJP. The influence of angiography table shields and height on patient and angiographer irradiation during interventional radiology procedures. Cardiovasc Intervent Radiol. 2007;30(3):448-454.

5. Kicken PJ, Bos AJ. Effectiveness of lead aprons in vascular radiology: results of clinical measurements. Radiology. 1995;197(2):473-478.

6. Chakeres DW, Wiatrowski W. Cerebral angiography: a device to reduce exposure to the eye lens. Radiology. 1984;152(2):534-535.

7. Kurokawa S, Yabe S, Takamura A, Ishizaki H, Aizawa S. Practical protective tools for occupational exposure: 1) double focus spectacles for the aged with highly refracted glass lens 2) remodeled barrier for radiation protection. Interv Neuroradiol J Peritherapeutic Neuroradiol Surg Proced Relat Neurosci. 2000;6(Suppl 1):33-42.

8. Balter S, Sones FM Jr, Brancato R. Radiation exposure to the operator performing cardiac angiography with U-arm systems. Circulation. 1978;58(5):925-932.

9. Kim KP, Miller DL. Minimising radiation exposure to physicians performing fluoroscopically guided cardiac catheterisation procedures: a review. Radiat Prot Dosimetry. 2009;133(4):227-233.

10. Neeman Z, Dromi SA, Sarin S, Wood BJ. CT fluoroscopy shielding: decreases in scattered radiation for the patient and operator. J Vasc Interv Radiol JVIR. 2006;17(12):1999-2004.

11. Finkelstein MM. Is brain cancer an occupational disease of cardiologists? Can J Cardiol. 1998;14(11):13851388 .

12. Kuon E, Birkel J, Schmitt M, Dahm JB. Radiation exposure benefit of a lead cap in invasive cardiology. Heart $\mathrm{Br}$ Card Soc. 2003;89(10):1205-1210.

13. Amoretti N, Lesbats V, Marcy PY, Hauger O, Amoretti ME, Maratos Y, et al. Dual guidance (CT and fluoroscopy) vertebroplasty: radiation dose to radiologists: how much and where? Skeletal Radiol. 2010;39(12):1229-1235.

14. Bondy ML, Scheurer ME, Malmer B, Barnholtz-Sloan JS, Davis FG, Il'yasova D, et al. Brain tumor epidemiology: consensus from the Brain Tumor Epidemiology Consortium. Cancer. 2008;113(7 suppl):1953-1968.

15. Chodick G, Bekiroglu N, Hauptmann M, Alexander BH, Freedman DM, Doody MM, et al. Risk of cataract after exposure to low doses of ionizing radiation: a 20-year prospective cohort study among US radiologic technologists. Am J Epidemiol. 2008;168(6):620-631.

16. Kohler BA, Ward E, McCarthy BJ, Schymura MJ, Ries
LA, Eheman C, Jemal A, et al. Annual report to the nation on the status of cancer, 1975-2007, featuring tumors of the brain and other nervous system. J Natl Cancer Inst. 2011;103(9):714-736.

17. Koukorava C, Carinou E, Simantirakis G, Vrachliotis TG, Archontakis E, Tierris C, et al. Doses to operators during interventional radiology procedures: focus on eye lens and extremity dosimetry. Radiat Prot Dosimetry. 2011;144(14):482-486.

18. Ohgaki H, Kleihues P. Epidemiology and etiology of gliomas. Acta Neuropathol (Berl). 2005;109(1):93-108.

19. Pflugbeil S, Pflugbeil C, Schmitz-Feuerhake I. Risk estimates for meningiomas and other late effects after diagnostic X-ray exposure of the skull. Radiat Prot Dosimetry. 2011;147(1-2):305-309.

20. Roguin A, Goldstein J, Bar O. Brain tumours among interventional cardiologists: a cause for alarm?: report of four new cases from two cities and a review of the literature. EuroIntervention J Eur Collab Work Group Interv Cardiol Eur Soc Cardiol. 2012;7(9):1081-1086.

21. Vano E, Gonzalez L, Fernández JM, Haskal ZJ. Eye lens exposure to radiation in interventional suites: caution is warranted. Radiology. 2008;248(3):945-953.

22. Wiemels J, Wrensch M, Claus EB. Epidemiology and etiology of meningioma. J Neurooncol. 2010;99(3):307-314.

23. International Commission on Radiological Protection. Statement on tissue reactions. 2011. http://www.icrp.org/docs/ ICRP $\%$ 20Statement \%20on \%20Tissue \%20Reactions.pdf. Accessed January 9, 2019.

24. Chohan MO, Sandoval D, Buchan A, Murray-Krezan C, Taylor CL. Cranial radiation exposure during cerebral catheter angiography. $J$ Neurointerventional Surg. 2014;6(8):633-636.

25. Mulconrey DS. Fluoroscopic radiation exposure in spinal surgery: in vivo evaluation for operating room personnel. J Spinal Disord Tech. 2016;29(7):E331-E335.

26. Rampersaud YR, Foley KT, Shen AC, Williams S, Solomito M. Radiation exposure to the spine surgeon during fluoroscopically assisted pedicle screw insertion. Spine (Phila Pa 1976). 2000;25(20):2637-2645.

27. Komemushi A, Tanigawa N, Kariya S, Kojima H, Shomura Y, Sawada S. Radiation exposure to operators during vertebroplasty. J Vasc Interv Radiol. 2005;16(10):13271332.

28. Goldstone KE, Wright IH, Cohen B. Radiation exposure to the hands of orthopaedic surgeons during procedures under fluoroscopic X-ray control. $\mathrm{Br} J$ Radiol. 1993;66(790):899-901.

29. Tenforde TS. Future role of the NCRP in radiation health protection. Health Phys. 2004;87(3):312-318; discussion 318-319.

30. Mariscalco MW, Yamashita T, Steinmetz MP, Krishnaney AA, Lieberman IH, Mroz TE. Radiation exposure to the surgeon during open lumbar microdiscectomy and minimally invasive microdiscectomy: a prospective, controlled trial. Spine (Phila Pa 1976). 2011;36(3):255-260.

31. Claus EB, Calvocoressi L, Bondy ML, Schildkraut JM, Wiemels JL, Wrensch M. Dental x-rays and risk of meningioma. Cancer. 2012;118(18):4530-4537.

32. Wall BF, Hart D. Revised radiation doses for typical X- 
ray examinations: report on a recent review of doses to patients from medical X-ray examinations in the UK by NRPB. National Radiological Protection Board. Br J Radiol. 1997;70(833):437-439.

Disclosures and COI: The authors report no conflict of interest or financial disclosures concerning the information presented or the findings specified.

Corresponding Author: Laila M. Mohammad,
MD, 1 University of New Mexico, Albuquerque, NM 87131; Phone: (505) 272-3401; Fax: (505) 272-6091; Email: LMoham@salud.unm.edu.

Published 22 February 2019

This manuscript is generously published free of charge by ISASS, the International Society for the Advancement of Spine Surgery. Copyright $\odot 2019$ ISASS. To see more or order reprints or permissions, see http://ijssurgery.com. 